\title{
PENERAPAN ANALISIS RESIKO TERHADAP KESEHATAN DAN KESELAMATAN KERJA(K3) PADA PT. $X$
}

\author{
Alfi Septianto ${ }^{1}$, Arie Restu Wardhani ${ }^{2 *}$ \\ ${ }^{1,2}$ Program Studi Teknik Industri, Fakultas Teknik, Universitas Widyagama Malang \\ *Email Korespondensi : arierestu@widyagama.ac.id
}

\begin{abstract}
ABSTRAK
Pentingnya implementasi Kesehatan dan Keselamatan Kerja (K3) menuntut semua perusahaan untuk mampu menerapkannya sehingga kesehatan dan keselamatan kerja karyawan dapat terjamin. Namun tidak semua perusahaan mampu menerapkan sistem ini, dikarenakan kelalaian karyawan yang tidak bersedia menggunakan alat pelindung diri, ataupun tidak adanya sanksi dan aturan yang ketat guna mengendalikan disiplin karyawan. Begitu pula dengan perusahaan di PT. X Malang yang merupakan perusahaan manufaktur yang memproduksi gula. Pada perusahan ini, terjadi kecelakaan kerja seperti terjatuh hingga patah tulang, terkena uap panas, terbakar, dan terkena potongan pipa. Oleh karena itu penerapan K3 sangat dibutuhkan dalam upaya proaktif mencegah kecelakaan kerja yang diakibatkan oleh kelalaian karyawan yang tidak menggunakan alat pelindung diri. Meski implementasi pencegahan kecelakaan seperti memasang papan informasi K3, serta pemberian alat pelindung diri. Penerapan analisis resiko dengan Failure Mode and Effect Analysis (FMEA) dilakukan agar dapat mengidentifikasi langkah apa yang harus dilakukan PT. X agar seluruh karyawan dapat mengimplementasikan budaya K3 di lingkungan kerjanya. Dari hasil analisa, maka diperoleh rekomendasi yaitu meningkatkan pemahaman karyawan melalui pelatihan $\mathrm{K} 3$, memperketat aturan K3 dengan pemberian reward dan punishment kepada karyawan, serta menerapkan budaya kerja $5 \mathrm{R}$ (Ringkas, Rapi, Resik, Rawat, dan Rajin).
\end{abstract}

Kata kunci : Failure Mode and Effect Analysis (FMEA), Kesehatan dan Keselamatan Kerja (K3), Diagram Sebab Akibat.

\begin{abstract}
The implementation of Occupational Health and Safety $(\mathrm{OHS})$ is pivotal for all companies. It requires the commitment from employees and employer to apply it, so the employee' health and safety can be guaranteed. However, not all companies can implement this system, due to the negligence from employees who are not willing to use personal protective equipment. It can be also because the rules are not too in controlling employees behaviour. It also occurs in PT. X Malang as the sugar company. At this company, work accidents such as falling to broken bones, exposed to hot steam, burning, and struck down by pipe occur. Therefore the application of OHS is a huge required to protect and to prevent work accidents caused by the negligence of employees who do not use personal protective equipment. Although the implementation of accident prevention such as installing OHS information boards, and providing personal protective equipment. The application of risk analysis with Failure Mode and Effect Analysis (FMEA) is carried out in order to identify what steps PT. X has undertaken further. Therefore, all employees can implement OHS culture in their work environment. From the results of the analysis, a recommendation is enhancing the skill and knowledge of the employees by training; tightening the OHS rules by giving rewards and punishments to employees. In addition, the need for the application of a $5 \mathrm{R}$ work culture (Clear-out, Configure, Clean, Conform, Custom).
\end{abstract}

Keywords : Failure Mode and Effect Analysis (FMEA), Occupational Health and Safety (OHS)), Cause and Effect Diagram.

\section{PENDAHULUAN}

Kecelakaan kerja dapat terjadi sewaktu-waktu di tempat kerja. Menurut (Hadiguna, 2012), kecelakaan merupakan suatu kejadian yang tidak dapat diduga kapan bisa terjadinya terhadap seseorang atau sekelompok orang pada suatu lingkungan perusahaan, yang dapat 
menimbulkan kerugian ringan sampai yang paling berat, dan menghentikan kegiatan pabrik secara total. Oleh karena itu, perlu adanya suatu sistem untuk antisipasi dan penanganan kecelakaan kerja yaitu sistem Kesehatan dan Keselamatan Kerja (K3). Sistem ini banyak diterapkan terutama pada perusahaan-perusahaan yang memahami arti penting K3.

Kesehatan kerja menunjukan kondisi fisik dan mental seseorang yang sehat dan terbebas dari gangguan fisik, mental, emosi atau rasa sakit yang disebabkan oleh lingkungan kerja yang dapat bekerja melebihi periode waktu yang ditentukan. Sedangkan keselamatan kerja merupakan perlindungan atas keamanan kerja yang dialami oleh seseorang pada saat bekerja baik secara fisik maupun mental dalam lingkungan pekerjaannya (Bangun, 2012).

Menurut Katman (2010), bahaya kimia terjadi ketika tenaga kerja cedera akibat zat kimia tertentu sehingga dapat mempengaruhi pekerjaannya serta proses kerja yang dapat menyebabkan cedera. Adapun bahaya lain yang terjadi diantaranya ditimbulkan oleh manusia, peralatan, material, dan proses. Adapun jenis bahaya dapat diklasifikasikan sebagai berikut: bahaya mekanis, bahaya listrik, bahaya fisik, bahaya biologis, bahaya kimia (Ramli, 2010).

Menurut (Ridley, 2008), penilaian risiko merupakan cara yang digunakan pimpinan untuk dapat mengelola dengan baik risiko yang dihadapi oleh pekerjaannya dan memastikan bahwa kesehatan dan keselamatan mereka tidak terkena risiko pada saat bekerja. Apabila suatu risiko terhadap kecelakaan dan penyakit akibat kerja telah diidentifikasi dan dinilai maka pengendalian risiko harus diimplementasikan untuk mengurangi risiko sampai batasbatas yang dapat diterima berdasarkan ketentuan peraturan dan standar yang berlaku. Hirarki pengendalian risiko adalah suatu urutanurutan dalam pencegahan dan pengendalian risiko yang mungkin timbul yang terdiri dari beberapa tingkatan secara berurutan (Tarwaka, 2014). Pengendalian risiko dilakukan dengan mengurangi kemungkinan atau keparahan dengan mengikuti hirarki sebagai berikut: eliminasi (elimination), substitusi (substitution), rekayasa teknik (engineering control), pengendalian administrasi (administration control), dan alat pelindung diri (personal protective equipment).

\section{METODE}

Metode Secara garis besar dapat diuraikan sebagai berikut:

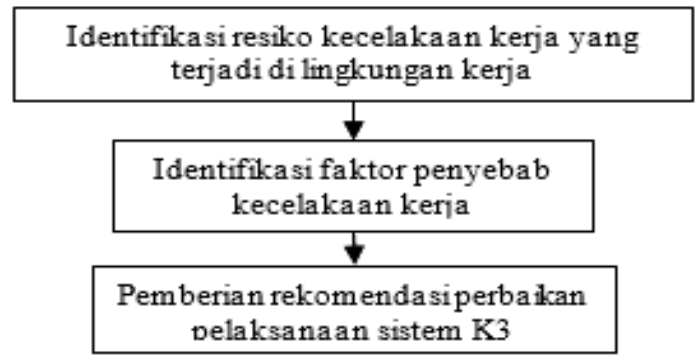

Gambar 1. Tahap penerapan analisis resiko untuk K3

\section{Identifikasi resiko kecelakaan kerja}

Tahapan awal dari perancangan ini adalah melakukan pengumpulan data dengan tujuan untuk merangkum teori-teori dasar, acuan secara umum dan khusus, serta untuk memperoleh informasi pendukung lainnya yang berhubungan dengan system K3. Setelah itu, melakukan identifikasi resiko dengan analisa FMEA. Data yang digunakan di sini adalah data sekunder, yaitu data jumlah kecelakaan selama 2 tahun yang lalu. 


\section{Identifikasi faktor penyebab kecelakaan kerja}

Dari hasil analisa FMEA maka dapat teridentifikasi nilai resiko tertinggi. Setelah itu, dilakukan analisa sebab akibat dengan menggunakan diagram sebab akibat. Setelah dilakukan rekomendasi berdasarkan wawancara dengan karyawan dan manajer produksi

\section{Pemberian rekomendasi perbaikan system K3}

Tahap ini dilakukan setelah analisa dengan FMEA dan diagram sebab akibat. Pada tahapan ini, karyawan di departemen produksi serta supervisor dan manager diwawancara untuk memperoleh rekomendasi untuk memperbaiki system K3.

\section{HASIL DAN PEMBAHASAN}

Data yang digunakan adalah data kecelakaan kerja 2 tahun terakhir. Terdapat kecelakaan sebanyak 60 orang. Sehingga perlu dilakukanya identifikasi kecelakaan lebih dulu agar setiap musim giling tiba para karyawan mematuhi kebijakan yang telah oleh perusahaan. Hasil observasi langsung dilakukan saat praktek kerja untuk memperoleh resiko kecelakaan yang ada dengan narasumber. Hasil dari temuan ditunjukan pada Tabel 1.

Tabel 1. Identifikasi Resiko Kecelakaan

\begin{tabular}{|l|l|l|}
\hline No. & Potensi Penyebab & Efek Yang ditimbulkan \\
\hline 1. & $\begin{array}{l}\text { Pekerja tidak menggunakan masker saat } \\
\text { bekerja }\end{array}$ & Kecelakaan Kerja \\
\hline 2. & Pekerja tidak menggunakan helmet saat bekerja & Kecelakaan Kerja \\
\hline 3. & Lantai Licin & Kecelakaan kerja \\
\hline 4. & Kebocoran pipa air & Kecelakaan Kerja \\
\hline 5. & $\begin{array}{l}\text { Timbulnya percikan api dari pekerja yang } \\
\text { melakukan Las }\end{array}$ & Kecelakaan Kerja \\
\hline 6. & Putaran mesin giling tidak stabil & Produk tidak standar \\
\hline 7. & Bahan olahan tidak memenuhi standar & Kualitas produk yang kurang \\
\hline 8. & Kualitas masakan D yang kurang bagus & Kualitas produk kurang \\
\hline 9. & Pengaruh asap gas kimia C0 & Kecelakaan Kerja \\
\hline 10. & Putaran mesin pada ST Puteran tidak stabil & Produk tidak standar \\
\hline 11. & Alat mesin yang kurang baik & Kualitas produk yang kurang \\
\hline 12. & Kapasitas alat yang digunakan kurang memadai & Kualitas produk yang kurang \\
\hline
\end{tabular}

Penilaian resiko dapat dilihat pada Tabel 2 berikut ini:

Tabel 2. Penilaian Resiko Yang Ditimbulkan

\begin{tabular}{|c|l|l|l|c|c|c|c|}
\hline \multirow{2}{*}{ No. } & Aktivitas & \multicolumn{1}{|c|}{$\begin{array}{c}\text { Faktor } \\
\text { Resiko }\end{array}$} & $\begin{array}{c}\text { Mode } \\
\text { kegagalan }\end{array}$ & Occurance & Severty & Detection & RPN \\
\hline 1 & \multirow{2}{*}{$\begin{array}{l}\text { Penggilingan } \\
\text { Tebu }\end{array}$} & $\begin{array}{l}\text { Terjatuh dari } \\
\text { ketinggian }\end{array}$ & Terkilir & 2 & 2 & 2 & 8 \\
\cline { 3 - 7 } & & $\begin{array}{l}\text { Patah } \\
\text { tulang kaki }\end{array}$ & 2 & 4 & 3 & 24 \\
\cline { 3 - 8 } & $\begin{array}{l}\text { Tertimpa } \\
\text { crane } \\
\text { pengangkut } \\
\text { tebu }\end{array}$ & $\begin{array}{l}\text { Patah } \\
\text { tulang }\end{array}$ & $\begin{array}{l}\text { Lecet pada } \\
\text { kaki dan } \\
\text { tangan }\end{array}$ & 3 & 3 & 3 & 36 \\
\hline 2 & $\begin{array}{l}\text { Pemurnian } \\
\text { Nira }\end{array}$ & $\begin{array}{l}\text { Pengaruh } \\
\text { asap gas } \\
\text { kimia C0 }\end{array}$ & $\begin{array}{l}\text { Sesak } \\
\text { napas dan } \\
\text { sakit paru- } \\
\text { paru }\end{array}$ & 4 & 4 & 2 & 24 \\
\hline
\end{tabular}

\section{8}




\begin{tabular}{|c|c|c|c|c|c|c|c|}
\hline & & $\begin{array}{l}\text { Pemanasan } \\
\text { pada Rotary } \\
\text { Sulfur Burner }\end{array}$ & $\begin{array}{l}\text { Luka } \\
\text { melepuh }\end{array}$ & 3 & 3 & 4 & 36 \\
\hline & & $\begin{array}{l}\text { Tidak } \\
\text { menggunakan } \\
\text { masker }\end{array}$ & $\begin{array}{l}\text { Penyakit } \\
\text { sesak } \\
\text { napas dan } \\
\text { batuk }\end{array}$ & 4 & 3 & 2 & 24 \\
\hline & & $\begin{array}{l}\text { Terkena } \\
\text { api/benda } \\
\text { panas }\end{array}$ & $\begin{array}{l}\text { Luka } \\
\text { melepuh }\end{array}$ & 2 & 3 & 5 & 30 \\
\hline \multirow[t]{4}{*}{3} & \multirow[t]{4}{*}{ Penguapan } & $\begin{array}{l}\text { Kebocoran } \\
\text { pipa air }\end{array}$ & $\begin{array}{l}\text { Terpeleset } \\
\text { dan jatuh }\end{array}$ & 3 & 4 & 3 & 36 \\
\hline & & $\begin{array}{l}\text { Tertimpa alat } \\
\text { berat. }\end{array}$ & $\begin{array}{l}\text { Patah } \\
\text { tulang }\end{array}$ & 4 & 2 & 2 & 16 \\
\hline & & $\begin{array}{l}\text { Alat mesin } \\
\text { yang kurang } \\
\text { baik }\end{array}$ & $\begin{array}{l}\text { Gagar otak } \\
\text { ringan }\end{array}$ & 4 & 3 & 2 & 24 \\
\hline & & Lantai Licin & $\begin{array}{l}\text { Luka patah } \\
\text { tulang }\end{array}$ & 3 & 4 & 3 & 27 \\
\hline \multirow[t]{2}{*}{4} & \multirow[t]{2}{*}{ Masakan } & $\begin{array}{l}\text { Terkena air } \\
\text { panas }\end{array}$ & $\begin{array}{l}\text { Luka } \\
\text { melepuh }\end{array}$ & 2 & 3 & 2 & 12 \\
\hline & & $\begin{array}{l}\text { Terkena uap } \\
\text { panas }\end{array}$ & $\begin{array}{l}\text { Mengalami } \\
\text { luka bakar }\end{array}$ & 3 & 5 & 3 & 45 \\
\hline
\end{tabular}

RPN tertinggi adalah pada aktifitas pemurnian nira yang menimbulkan asap kimia gas $\mathrm{CO}_{2}$ yang dapat menimbulkan sesak napas dan paru-paru dengan nilai RPN 80. Maka prioritas kecelakaan kerja yang harus ditangani terlebih dahulu adalah pengaruh gas $\mathrm{CO}_{2}$ akibat proses pemurnian nira.

Setelah diketahui kecelakaan yang memerlukan prioritas utama, yaitu pengaruh gas $\mathrm{CO}_{2}$, maka dilakukan terlebih dahulu analisis penyebab dari pengaruh tersebut. Untuk itu diperlukan sebuah tool yang biasa dipakai, yaitu Diagram Fisbhone. Dalam permasalahan ini diagram fisbhone digunakan untuk mencari penyebab permasalahan kecelakaan kerja yang terjadi pada stasiun pemurnian. Analisis akar penyebab kecelakaan menggunakan diagram fisbhone adalah seperti pada Gambar 2.

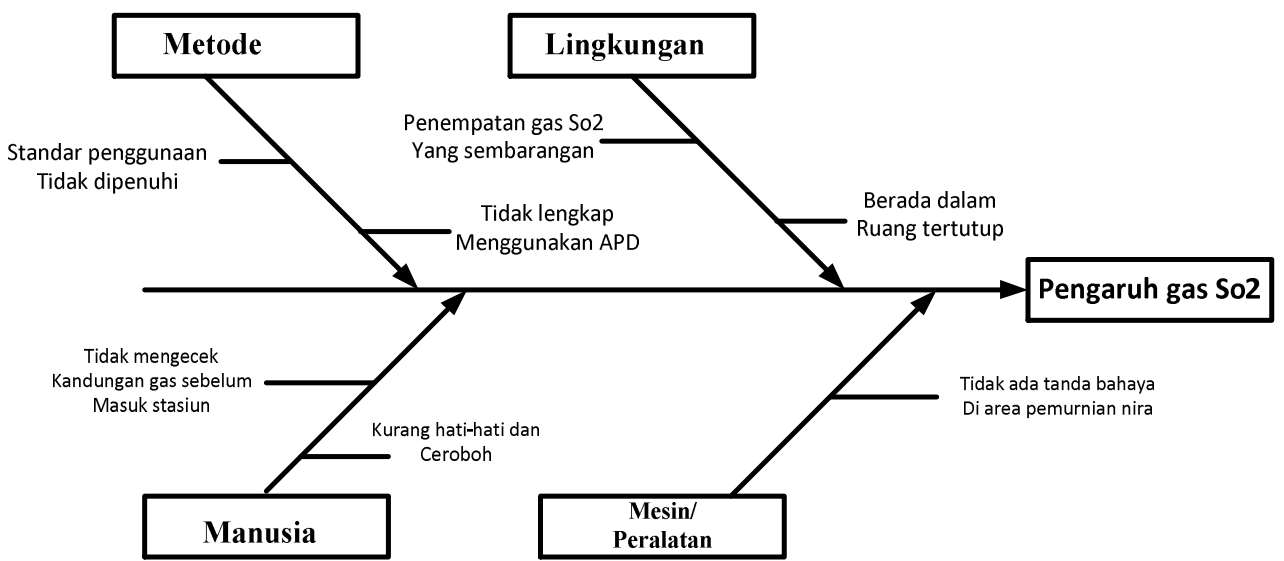

Gambar 2. Diagram Sebab akibat penyebab kecelakaan di Stasiun Pemurnian 
1. Manusia

Faktor yang dapat menyebabkan terjadinya suatu kecelakaan kerja pada manusia adalah kurangnya koordinasi pada saat pelaksanaan pekerjaan tersebut. Sikap kerja yang dapat menimbulkan kecelakaan kerja adalah ceroboh atau kurang hati-hati serta tidak mengecek kandungan gas sebelum masuk stasiun. Serta tidak mematuhi aturan yang sudah ditetapkan.

\section{Metode}

Metode yang digunakan dalam menggunakan campuran gas $\mathrm{SO}_{2}$ yang dapat terhirup oleh pekerja karena pekerja sendiri tidak menerapkan standar kerja yang dipenuhi perusahaan, seperti tidak menggunakan alat pelindung diri seperti masker, kaca mata dan lain-lain. Serta kurangnya pengawasan dari pihak kepala bidang seksi untuk memberikan intruksi pentingnya penggunaan APD ( Alat Pelindung Diri).

\section{Lingkungan}

Banyaknya bahan kimia dan gas lain yang bercecer di lokasi stasiun pemurnian nira yang berpotensi terhirup oleh pekerja berpengaruh terhadap kesehatan pekerja, serta ruangan pengolahan gas yang tertutup membuat gas tidak bisa keluar dari ruangan.

Rekomendasi yang dapat dilakukan adalah menyarankan kepada pihak menejemen pabrik perusahaan agar memperketat aturan tentang K3 kepada semua karyawan perusahaan agar bisa mengurangi kecelakaan terhadap karyawan baik itu karyawan tetap maupun karyawan kontrak. Dengan adanya aturan yang ketat maka setiap karyawan dituntut untuk disiplin dalam melakukan pekerjaan dengan menggunakan Alat Pelindung Diri (APD). Kemudian mengadakan pelatihan K3 dan mewajibkan karyawan memiliki sertifikat K3.

Selain karyawan displin dalam menggunakan APD alangkah baiknya perusahaan juga harus menerapkan budaya kerja $5 \mathrm{~S}$ pada PT. X. Apabila pada suatu perusahaan dapat menerapkan budaya $5 \mathrm{~S}$ dengan baik dan benar maka setiap pekerjaan yang dilakukan oleh karywan akan mencapai efektivitas dan efisien, menciptakan manusia yang berdisiplin tinggi, menghargai waktu, bekerja keras, berorientasi sukses dan berorientasi kepada Integritas dan hal yang positif lainnya.

\section{DAMPAK DAN MANFAAT}

Penerapan analisis resiko pada $\mathrm{K} 3$ ini sangat bermanfaat bagi perusahaan utuk dapat menentukan langkah selanjutnya untuk memperbaiki system K3. Selain itu dapat diketahui resiko terbesar, sehingga fokus perusahaan dapat dilakukan pada resiko terbesar.

\section{KESIMPULAN}

Hasil menunjukkan, bahwa resiko tertinggi ada pada pemurnian nira dengan tinggi RPN sebesar 80. Oleh karena itu, berdasarkan diagram sebab akibat, maka dari faktor manusia, perlu adanya SOP yang jelas, reward, dan punishment, pelatihan K3 yang dapat mencegah suatu kecelakaan kerja pada manusia. Dari segi metode, juga diperlukan SOP proses produksi yang jelas, penggunaan alat pelindung diri, serta koordinasi yang bai kantar karyawan. Dari segi Lingkungan, perlu penerapan budaya $5 \mathrm{R}$ sehingga aktivitas kerja menjadi lebih produktif. 


\section{UCAPAN TERIMA KASIH}

Terimakasih sebesar-besarnya kami haturkan kepada seluruh civitas akademika Universitas Widyagama Malang.

\section{REFERENSI}

Bangun, W. (2012) 'Manajemen Sumber Daya Manusia', Jakarta: Erlangga.

Hadiguna, R. A. (2012) 'Model Penilaian Risiko Berbasis Kinerja untuk Rantai Pasok Kelapa Sawit Berkelanjutan di Indonesia', Jurnal Teknik Industri. DOI: 10.9744/jti.14.1.13-24.

Katman (2010) 'Modul Menerapkan Prosedur Keselamatan, Kesehatan Kerja Dan Lingkungan Tempat Kerja', Bandar Lampung: Erlangga.

Ramli, S. (2010) 'Petunjuk Praktis Manajemen Kebakaran (Fire Management)', Jakarta: Erlangga.

Ridley, J. (2008) 'Ikhtisar Kesehatan dan Keselamatan Kerja', Jakarta: Erlangga.

Tarwaka (2014) 'Occupational Safety and Health, Management and implementation of Occupational Health and Safety at work', In: Surakarta: Harapan Press. 